\title{
Analyzing the Mara River Basin Behaviour through Rainfall-Runoff Modeling
}

\author{
Anne M. Birundu1, Benedict M. Mutua ${ }^{2 *}$ \\ ${ }^{1}$ Murang'a University College, Nairobi, Kenya \\ ${ }^{2}$ Deputy Vice-Chancellor (Planning, Partnerships, Research and Innovation), Kibabii University, Bungoma, Kenya \\ Email: mbirundu1@gmail.com, `bmmutua@kibu.ac.ke
}

How to cite this paper: Birundu, A.M. and Mutua, B.M. (2017) Analyzing the Mara River Basin Behaviour through Rainfall-Runoff Modeling. International Journal of Geosciences, 8, 1118-1132. https://doi.org/10.4236/ijg.2017.89064

Received: July 5, 2017

Accepted: September 19, 2017

Published: September 22, 2017

Copyright (c) 2017 by authors and Scientific Research Publishing Inc. This work is licensed under the Creative Commons Attribution International License (CC BY 4.0).

http://creativecommons.org/licenses/by/4.0/

(c) (i) Open Access

\begin{abstract}
Hydrological models are considered as necessary tools for water and environmental resource management. However, modelling poorly gauged watersheds has been a challenge to hydrologists and hydraulic engineers. Research done recently has shown the potential to overcome this challenge through incorporating satellite based hydrological and meteorological data in the measured data. This paper presents results for a study that used the semi-distributed conceptual HBV Light Model to model the rainfall-runoff in the Mara River Basin, Kenya. The model simulates runoff as a function of rainfall. It is built on the basis established between satellite observed and in-situ rainfall, evaporation, temperature and the measured runoff. The model's performance and reliability were evaluated over two sub-catchments namely: Nyangores and Amala in the Mara River Basin using the Nash-Sutcliffe Efficiency which the model referred to as $R_{\text {eff }}$ and the coefficient of determination $\left(R^{2}\right)$. The $R_{\text {eff }}$ for Nyangores and Amala during the calibration and (validation) period were $0.65(0.68)$ and $0.59(0.62)$ respectively. The model showed good flow simulations particularly during the recession flows, in the Nyangores sub-catchment whereas it simulated poorly the short term fluctuations of the high-flow for Amala sub-catchment. Results from this study can be used by water resources managers to make informed decision on planning and management of water resources.
\end{abstract}

\section{Keywords}

Hydrological Models, Satellite Data, HBV Light Model, Mara River Basin

\section{Introduction}

Kenya is characterized as water stressed country since the per capita water 
availability is at $792 \mathrm{~m}^{3}$ with a population of approximately 40 million people [1]. With the increasing population, expanding urbanization, modernised lifestyles, climate changes and other global changes, the pressure for sustainable planning and management of the finite water resources is more evident than ever.

This paper focuses on a study that was carried out in the Mara River Basin that cuts across Kenya and Tanzania. The Mara River Basin (MRB) covering a drainage area of $13,750 \mathrm{~km}^{2}$ is one of the catchments of Lake Victoria and forms part of the Upper Nile Basin. The Mara River (MR) which is about $395 \mathrm{~km}$ long is one of the Rivers supplying water into Lake Victoria throughout the year. The River originates from Mau Forest Complex which forms part of the upper basin. The Mara River Basin (MRB) is characterized by the extensive cultivated land and forested areas in the upper part, tropical savannah vegetation in the middle of the basin and one of the world famous Mara-Serengeti ecosystem towards the lower part of the Mara wetland form part of the extreme lower side of the Basin on the Tanzania side where the River drains into Lake Victoria.

The Mara River Basin faces numerous interactions that require effective management to ensure sustainability of its water resources since many livelihoods depend on it. The basin has undergone several changes over the last 50 years as a result of increased human population [2].

The flow regime in the Mara River has changed over the years due to catchment degradation. For instance, [3] in the study on Modelling the Impact of Land-Cover and Rainfall Regime Change Scenarios on the Flow of Mara River found out that there has been a decline in the dry season flow and increased peak flood frequency in recent years. In another study by [4] where these researchers applied the USGS Geospatial Stream Flow Model in studying the impact of land use/cover on the hydrology of MRB, it was found out that forests and savannah grasslands have been cleared and turned into agricultural lands. In addition, the long-term monitoring also identified several areas of concern in the upper catchment of the basin. For instance, the results showed that the Amala sub-catchment has experienced higher decline in average monthly flow levels over the last 15 years, transported higher sediment load per unit catchment area and has generally lower water quality than the Nyangores sub-catchment, suggesting land degradation in this sub-catchment may be responsible for declines in water quantity and quality in the Mara River basin.

In order to effectively plan for the water resource use and to protect it under the changing conditions, application of basin runoff models that can simulate flow regimes under different scenarios of change [5] is required. However, the availability of long term spatial and temporal quality hydro-meteorological data has been a challenge in many river basins in Kenya. In order to overcome this challenge, this study used the satellite observed rainfall products and the $30 \mathrm{~m}$ resolution Shuttle Radar Topography Mission (SRTM) DEM which were derived from open sources. The study applied a conceptual hydrological model, the $\mathrm{Hy}^{-}$ 
drologiska Byrans Vattenavdelning model (HBV Light Model) for run-off simulation of the measured rainfall.

\section{Materials and Methods}

The Mara River Basin which is a trans-boundary basin covers approximately $13,750 \mathrm{~km}^{2}$. It lies between South Western Kenya and North Western Tanzania at between longitudes $33^{\circ} 47^{\prime} \mathrm{E}$ and $35^{\circ} 47^{\prime} \mathrm{E}$ and Latitudes $0^{\circ} 28^{\prime} \mathrm{S}$ and $1^{\circ} 52^{\prime} \mathrm{S}$. The Napuiyapui swamp in the Mau Forest Complex, is the source for the Mara River where it flows at an altitude of approximately 3000 metres above sea level (m.a.s.l) South West before draining into Lake Victoria in Musoma Tanzania at an altitude of 1134 metres above sea level [6]. The Nyangores and Amala Rivers are the two main perennial tributaries of the Mara River and their respective sub-basins form part of the Upper catchment. The other tributaries are; Talek, Sand and Engare Ngobit rivers on the Kenyan side and the Bologonja River on the Tanzania side (Figure 1). The amount of annual rainfall in the basin varies from $1400 \mathrm{~mm}$ in the hills of the Mau Forest to $500-700 \mathrm{~mm}$ in the dry plains of north-west Tanzania [7].

The study used the HBV model which simulates the daily discharge using input variables of rainfall, temperature and potential evapotranspiration [8]. The input data collected were checked for consistency as well as filling in the missing data gaps for precipitation, discharge and temperature datasets. The main approach used was the correlations between the three hydro-meteorological stations (Narok, Kericho and Kisii) data. Thereafter, multiple linear regressions were used to develop relationship equations which were then used to fill the missing data gaps.

The records of only three out of the thirty six hydro-meteorological stations on the Kenyan side as shown in Figure 2 were processed. The data was recorded daily at 0900 hours and was expressed in millimetres per day ( $\mathrm{mm} /$ day). The area average precipitation $\mathrm{P}_{\text {area }}$ was calculated as weighted mean of precipitation stations in and around the catchment. This was achieved through use of the Thiessen polygons.

The temperature was calculated as weighted mean of the stations in and around the catchment after the missing data was filled using multiple linear regressions. The data was obtained from the Kenya Metrological Department. Compared to other rivers within the Mara River basin, Nyangores and Amala Rivers have long term daily discharge data records. Readings of water levels for the two rivers were taken twice each day daily in the morning at $0600 \mathrm{hrs}$ and in the evening at 1800 hrs. Rating curves were then used to estimate daily average discharges.

\subsection{Application of Hydrologiska Byrans Vattenavdelning (HBV Light) Model}

The HBV light model which is a semi distributed conceptual model was selected 


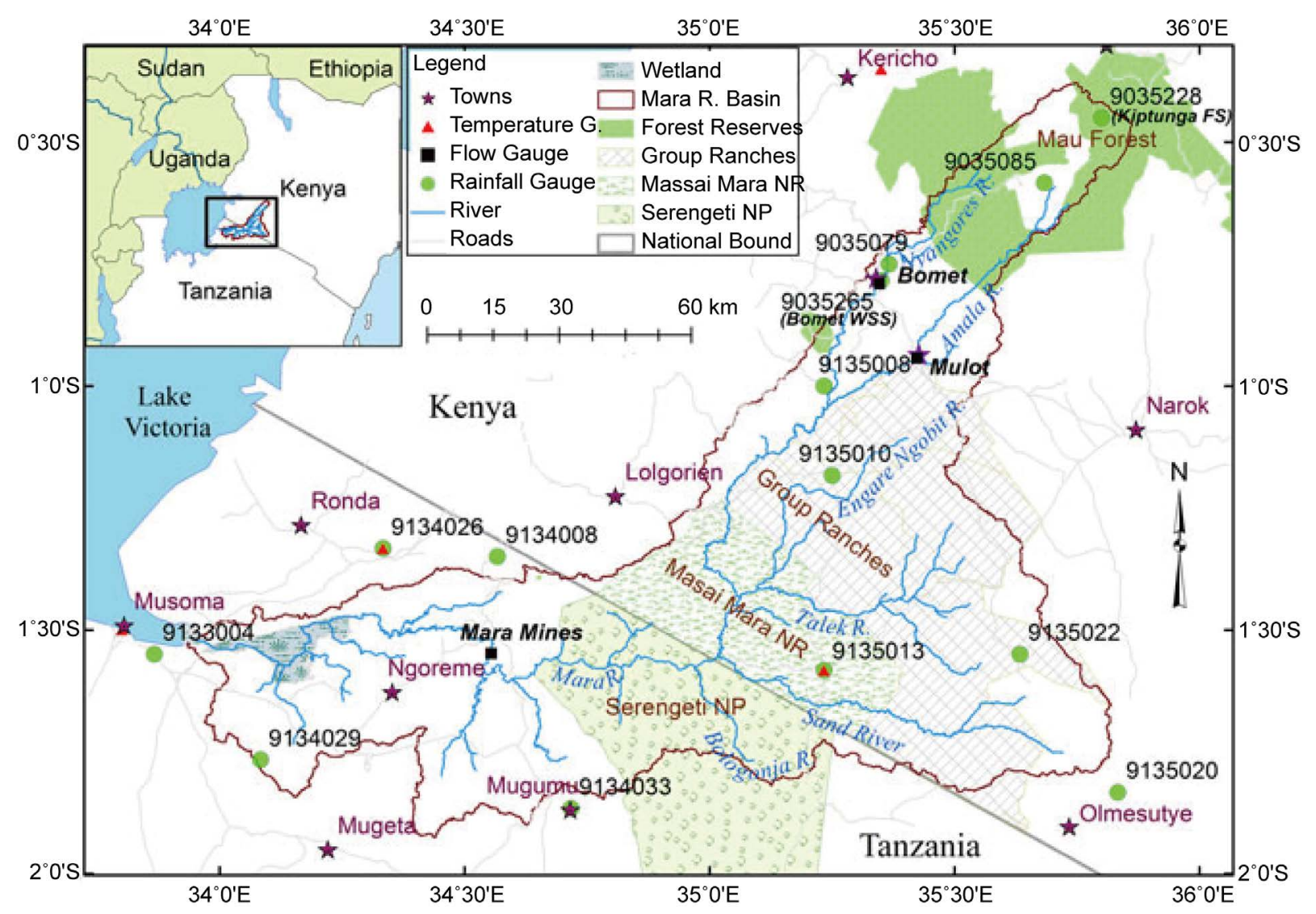

Figure 1. Site Map of the trans-boundary Mara River Basin, showing the Mara River with its tributaries. Source: (Melesse, 2012).

to simulate the rainfall runoff processes in the two sub-catchments. The model was selected because of its suitability that has been demonstrated under different hydro climatic conditions in the world [9] [10]. The general structure and equations of HBV light model is summarized in Figure 3. The reservoirs are connected to each other by means of exchange fluxes which define the amount of water between the different zones. Equations (1) and (2) give the general water balance. The HBV light model has four routines which include; the snow pack (not used in this research), soil moisture, response function and routing routines [11] as summarized in Figure 3.

$$
\frac{\Delta S}{\Delta t}=\text { Input }- \text { Output }
$$

where; $\Delta S=$ Change in Storge and $\Delta t=$ Change over time

$$
\mathrm{P}-\mathrm{E}-\mathrm{Q}=\frac{\mathrm{d}}{\mathrm{d} t}(\mathrm{SP}+\mathrm{SM}+\mathrm{UZ}+\mathrm{LZ}+\text { lakes })
$$

where; $\mathrm{P}$ is precipitation, $\mathrm{E}$ is evaporation, $\mathrm{Q}$ is runoff, $\mathrm{SP}$ is the snow pack, and SM is the soil moisture. The UZ and LZ are the upper and lower ground water zones.

The HBV light model uses sub-catchments as the primary hydrological units. 


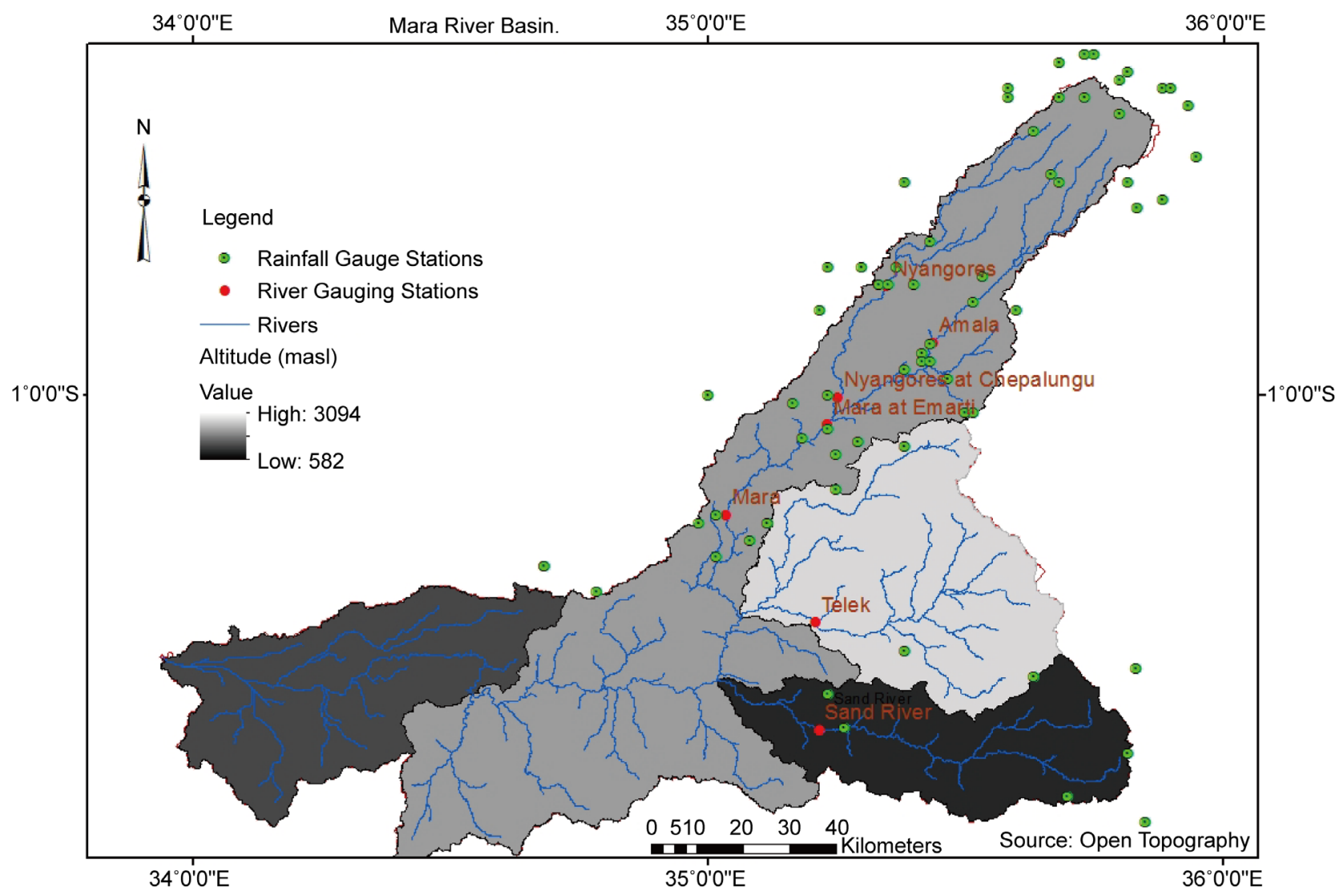

Figure 2. Processed SRTM DEM showing the Elevation, Rainfall gauging stations and the River gauging stations of the Mara River Basin.

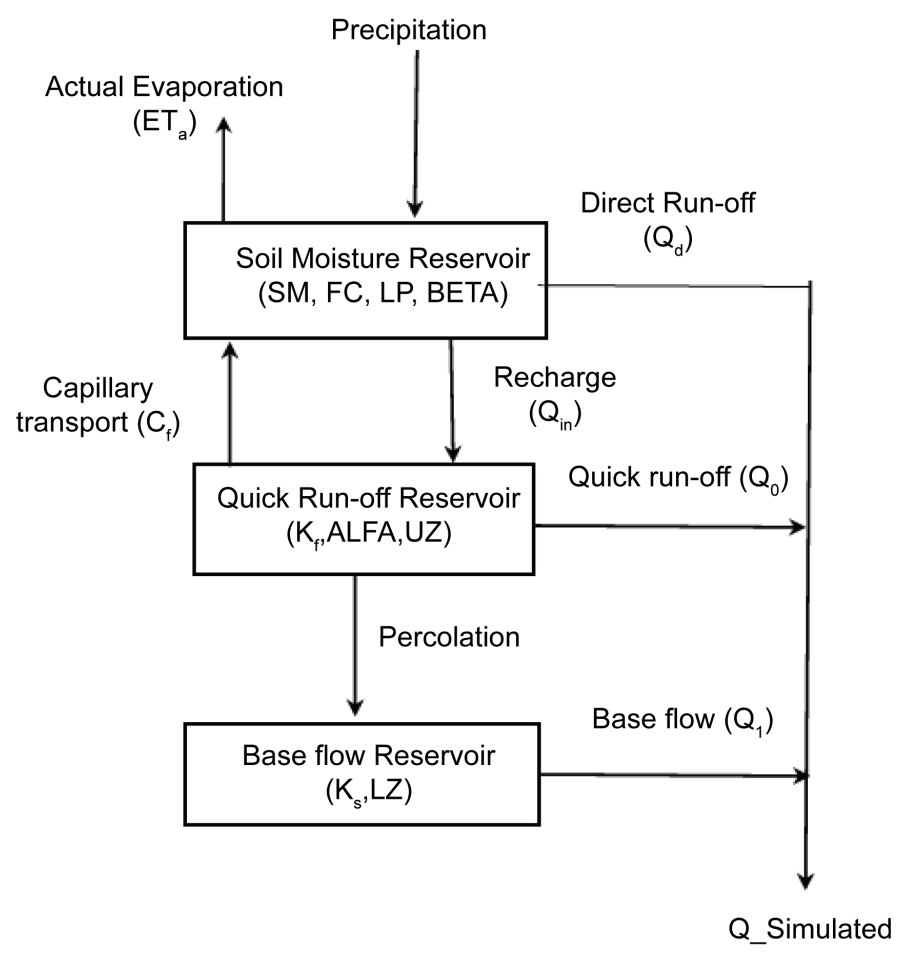

Figure 3. General structure of the HBV model. 
The catchments classifications of land use, and area-elevations are used as input into the model. The model can be run with daily precipitation time series data but higher resolution can also be used in the model.

The channel routing is by a triangular weighing function through MAXBAS (length of weighing function). The soil moisture threshold for reduction of evapotranspiration defines LP. The maximal flow from the upper to lower groundwater box is defined by $\mathrm{P}_{\mathrm{ERC}} ; \beta$ is shape coefficient for the non-linear storage behaviour of the soil zone.

The model uses a warming up period of one year [12]. The warm-up period refers to the time that the simulation will run before the final results are collected and it allows the acclimatization of input data-set to the running conditions normal to the system being simulated.

\subsection{Model Run}

The model was run in dynamic mode on a daily basis in order to simulate a combined period of eleven (11) years translating to a total of 4017 time steps. The model calibration and validation was done by through trial and error method. The Monte Carlo runs were generated to investigate the catchment response characteristics, and to explore physically realistic model's parameters ranges. Initial Monte Carlo simulations were generated using parameter values from the literature (tuned with preliminary model runs) to define possible parameter ranges as shown in Table 1. However, the time dependent units change for simulations with more aggregated time steps ( 15 and 30 days) were applied.

Table 1. Parameters and their ranges applied during the Monte Carlo Simulations.

\begin{tabular}{|c|c|c|c|c|}
\hline Parameter & Explanation & Unit & Minimum & Maximum \\
\hline \multicolumn{5}{|c|}{$\begin{array}{l}\text { Soil and evaporation } \\
\text { routine: }\end{array}$} \\
\hline $\mathrm{FC}$ & Maximum soil moisture storage & $\mathrm{mm}$ & 100 & 550 \\
\hline LP & $\begin{array}{l}\text { Soil moisture threshold for } \\
\text { reduction of evaporation }\end{array}$ & $3 / 4$ & 0.3 & 1 \\
\hline$\beta$ & Shape coefficient & $3 / 4$ & 1 & 5 \\
\hline \multicolumn{5}{|c|}{ Groundwater and response routine: } \\
\hline $\mathrm{K}_{0}$ & Recession coefficient & $\mathrm{d}^{-1}$ & 0.1 & 0.5 \\
\hline $\mathrm{K}_{1}$ & Recession coefficient & $d^{-1}$ & 0.01 & 0.2 \\
\hline $\mathrm{K}_{2}$ & Recession coefficient & $d^{-1}$ & $5.00 \mathrm{E}-05$ & 0.1 \\
\hline $\mathrm{UZL}$ & Threshold for $\mathrm{K}_{0}$-outflow & $\mathrm{mm}$ & 0 & 70 \\
\hline PERC & $\begin{array}{l}\text { Maximal flow from upper to lower } \\
\text { GW-box }\end{array}$ & $\mathrm{mm} / \mathrm{d}$ & 0 & 4 \\
\hline \multicolumn{5}{|l|}{ Routing routine: } \\
\hline MAXBAS & $\begin{array}{l}\text { Routing, length of } \\
\text { weighting function }\end{array}$ & $\mathrm{d}$ & 1 & 2.5 \\
\hline
\end{tabular}


Different parameter sets were produced by running more than 300,000 Monte Carlo Simulations (MCS) for each catchment representation of the Nyangores and Amala sub-catchments on daily time steps. The efficiency $\mathrm{R}_{\text {eff }}$ value was used for assessment of simulations by the HBV model. The $\mathrm{R}_{\text {eff }}$ value compares the prediction by the model with the simplest possible prediction, a constant value of the observed mean value over the entire period. Several model parameter sets with $\mathrm{R}_{\mathrm{eff}}$ comparable to the highest values were obtained.

\section{Results and Discussions}

The results show that in the Nyangores sub-catchment, a $R_{\text {eff }}>0.65$ was obtained after running, 250,000 MCS. In the case of Amala sub-catchment, a $R_{\text {eff }}>0.59$ was obtained after running 100,000 simulations of the Monte Carlos. Based on the Nash-Sutcliffe Efficiency criteria, the performance of the model was within acceptable range as per the selected performance criteria.

In addition, to visual observation of the hydrographs and evaluation of low flows ( $\log \mathrm{R}_{\text {eff }}$ ), the values of $\mathrm{R}_{\text {eff }}>0.65$ and $\mathrm{R}_{\text {eff }}>0.59$ were considered satisfactory. The calibration results are shown in Figure 4 below and Table 2 together with their corresponding statistical measures for model performance assessment.

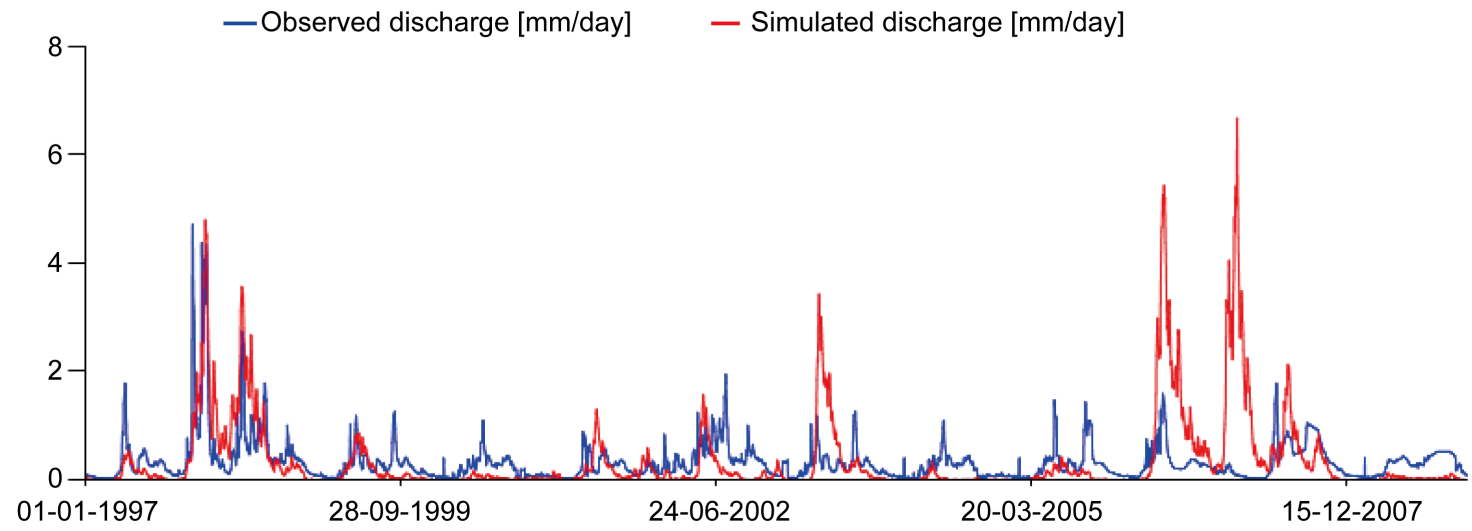

(a)

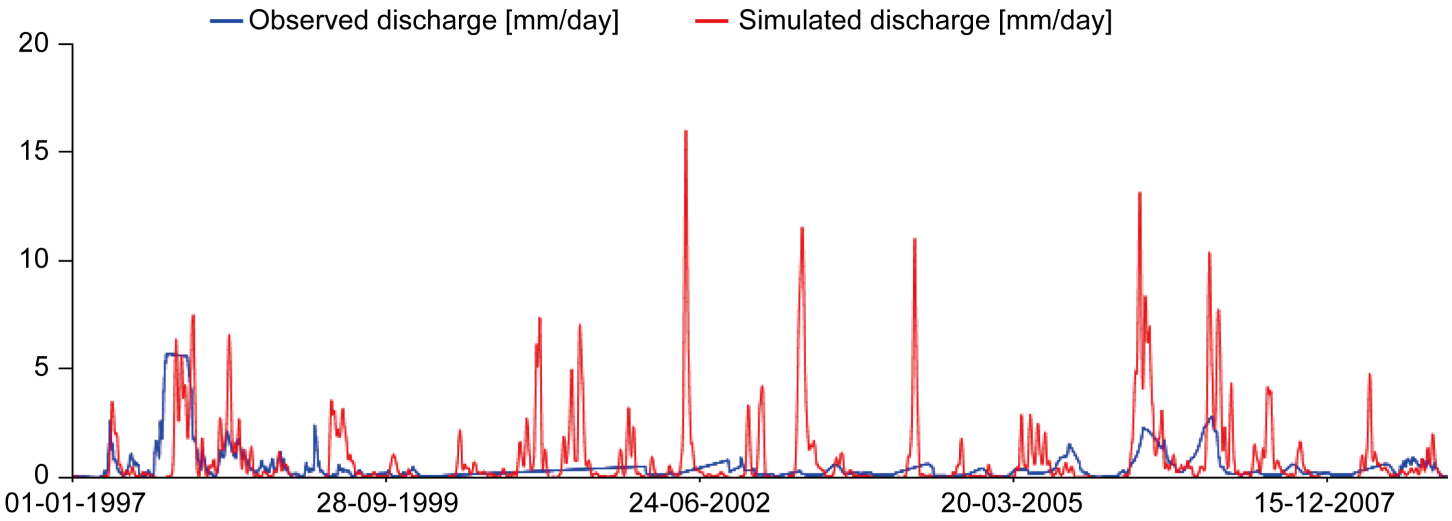

(b)

Figure 4. (a) and (b). Simulated and Observed discharge in $\mathrm{mm} /$ day for Nyangores and Amala Sub-catchments respectively for the calibration. (a). Nyangores Sub-catchment; (b). Amala Sub-catchment. 
Table 2. Calibration and Validation parameters and model efficiency results for Nyangores and Amala Sub-catchments for the period of 1996-2008 and 2009-2013 respectively.

\begin{tabular}{|c|c|c|c|c|}
\hline Calibration/Validation & Parameters & Units & $\begin{array}{l}\text { Nyangores } \\
\text { catchment }\end{array}$ & $\begin{array}{c}\text { Amala } \\
\text { catchment }\end{array}$ \\
\hline \multirow[t]{11}{*}{ Parameters } & FC & $(\mathrm{mm})$ & 408.61 & 350.00 \\
\hline & LP & $(3 / 4)$ & 0.32 & 0.9 .00 \\
\hline & $\beta$ & $(3 / 4)$ & 5.20 & 12.00 \\
\hline & $\mathrm{K}_{0}$ & $\left(d^{-1}\right)$ & 0.11 & 0.05 \\
\hline & $\mathrm{K}_{1}$ & $\left(\mathrm{~d}^{-1}\right)$ & 0.11 & 0.99 \\
\hline & $\mathrm{K}_{2}$ & $\left(\mathrm{~d}^{-1}\right)$ & 0.92 & 0.99 \\
\hline & UZL & $(\mathrm{mm})$ & 46.75 & 56.36 \\
\hline & PERC & $(\mathrm{mm} / \mathrm{d})$ & 0.10 & 0.45 \\
\hline & MAXBAS & (d) & 1.50 & 15.00 \\
\hline & $\mathrm{R}_{\mathrm{eff}}$ & $(3 / 4)$ & 0.62 & 0.48 \\
\hline & $\log \mathrm{R}_{\text {eff }}$ & $(3 / 4)$ & 0.60 & 0.46 \\
\hline \multirow[t]{4}{*}{ Calibration } & $\mathrm{R}^{2}$ & $(3 / 4)$ & 0.73 & 0.65 \\
\hline & $\Delta \mathrm{Q}$ & $(\mathrm{mm} / \mathrm{a})$ & 0.00 & 0.00 \\
\hline & $\mathrm{R}_{\text {eff }}$ & $(3 / 4)$ & 0.65 & 0.59 \\
\hline & $\log R_{\text {eff }}$ & $(3 / 4)$ & 0.63 & 0.57 \\
\hline \multirow[t]{2}{*}{ Validation } & $\mathrm{R}^{2}$ & $(3 / 4)$ & 0.75 & 0.69 \\
\hline & $\Delta \mathrm{Q}$ & $(\mathrm{mm} / \mathrm{a})$ & -8.00 & -131.00 \\
\hline
\end{tabular}

From the visual observation of the hydrographs in Figure 4, it indicates generally good flow simulations in particular during the recession flows, in the Nyangores sub-catchment with a bit of high peaks towards the end of the simulation period. In comparison to the Amala sub-catchment, the short-term fluctuations during the high-flow season were not modelled well. In fact, the model overestimated the discharge as clearly shown in the hydrograph. The mean annual $(\Delta Q)$ differences between observed and simulated runoff was negligible. The results show a good relationship between the simulated and observed low flows in the Nyangores catchment with a $\log \mathrm{R}_{\text {eff }}>0.63$ compared to the $\log$ $\mathrm{R}_{\text {eff }}>0.57$ for the Amala sub-catchment. The coefficient of determination $\mathrm{R}^{2}$ was $>0.73$ and $>0.65$ for the Nyangores and Amala sub-catchments respectively. The parameter values for which the model was highly sensitive (yielding good simulations) only for comparable small intervals, were related to the soil moisture storage and runoff generation routine as shown in the standardized parameter values given in Table 2. The Table shows the smallest and largest parameter values that produced $R_{\text {eff }}>0.65$ and $>0.59$ for the Nyangores and Amala respectively. A satisfactory model performance $\left(R_{\text {eff }}>0.65\right)$ was attained in Nyangores with a soil moisture storage, FC, in the range of $408 \mathrm{~mm}<\mathrm{FC}<514$ $\mathrm{mm}$ near the maximum parameter range whereas in Amala, the FC was lower, 
ranging between $265 \mathrm{~mm}<\mathrm{FC}<350 \mathrm{~mm}$. The run-off routine parameters $\mathrm{P}_{\mathrm{ERC}}$ (maximum flow from upper to lower reservoirs) and UZL (threshold for $\mathrm{K}_{0}$ flow) and the soil routine parameter, $\beta$ (shape coefficient) were found to be the most sensitive parameters in that order in Nyangores sub-catchment. In Amala, the only sensitive parameters were $\mathrm{K}_{2}, \mathrm{P}_{\mathrm{ERC}}$ and $\mathrm{K}_{1}$ respectively in that order. The $\mathrm{K}_{0}$ values for Nyangores and Amala were found to be 0.11 and 0.05 respectively.

This implies that a major portion of the rainfall received in Amala leaves the catchment quickly as direct runoff, while the rainfall falling in Nyangores is stored and later on released as base flow. The difference in sensitivity of the parameters reflects on the different hydrological processes between the two sub-catchments suggesting different dominant run-off generation processes.

The validation period for the two sub-catchments was done for the period between $1^{\text {st }}$ January, 2009 to $30^{\text {th }}$ November, 2013 and the results indicated better efficiencies as compared to the calibration as shown by the hydrographs in Figure 5 and Table 2.

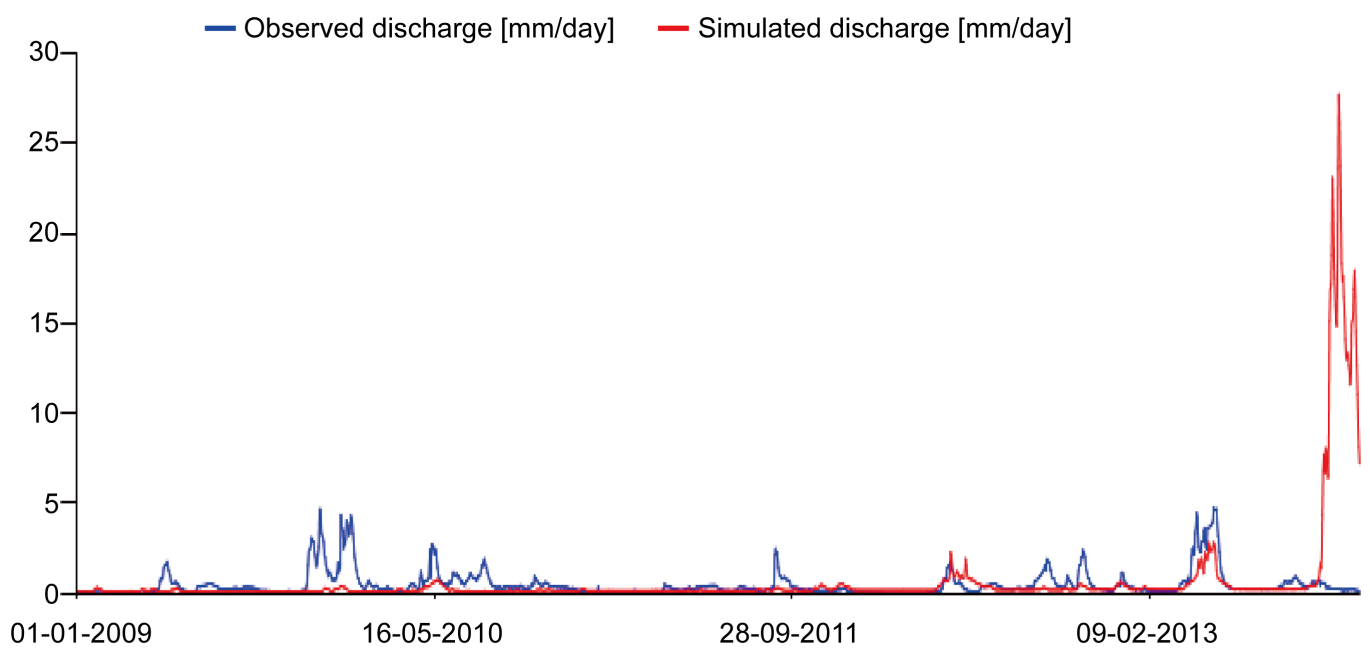

(a)

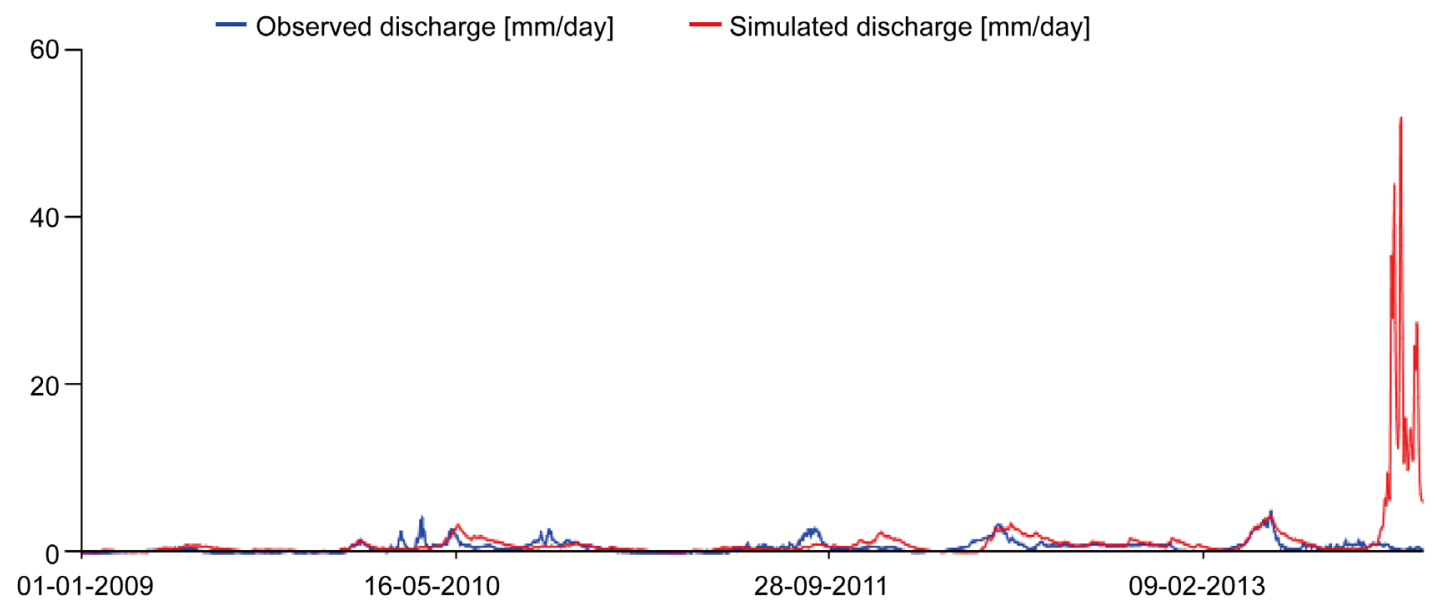

(b)

Figure 5. (a) and (b). Simulated and Observed discharge in $\mathrm{mm}$ /day for Nyangores and Amala Sub-catchments above and below respectively for the validation. (a). Nyangores Sub-catchment; (b). Amala Sub-catchment. 
From Table 2, the results show that the $\mathrm{R}_{\text {eff }}$ values for Nyangores and Amala sub-catchments were $R_{\text {eff }}>0.68$ and $R_{\text {eff }}>0.62$ respectively. These efficiencies were generally good, even though the model overestimated the observed discharge by about $131 \mathrm{~mm} / \mathrm{a}$ (70\%) in the Amala sub-catchment. Low flow simulations were acceptable with Nyangores and Amala having $\log \mathrm{R}_{\text {eff }}>0.64$ and $\log$ $\mathrm{R}_{\text {eff }}>0.59$ respectively. The model showed better performance during the validation period as compared to the calibration period posting higher coefficient of determination $\mathrm{R}^{2}>0.75$ and $\mathrm{R}^{2}>0.69$ for Nyangores and Amala respectively. The reason as to why the model simulations during this period were better than the calibration period could be attributed to better data quality (fewer missing data) for the later years. In addition, results indicate that the HBV Light model has the ability to reproduce good rainfall-run-off relation during mean and low flow periods.

\subsection{Assessment of Model Performance}

In order to obtain a process-based representation of the hydrological characteristics in the two sub-catchments, manual adjustments of the model parameters were done following Monte Carlo simulations (MCS). An automatic calibration of the model was avoided because of the limitations of data quality and quantity. The MCS was carried out to identify the sensitivity of the catchments' runoff generation characteristics, and to explore ranges of model parameters. Sensitivity analyses of model parameters was conducted through: (i) Assessing model results for different model structures (two catchment representations), and; (ii) Analysing the results of the MCS runs (over a 100,000 model runs for each catchment representations). The ranges for model parameters for the MCS analysis were kept wide as shown in Table 2 above; however, a search for suitable parameter sets with no plausible parameter values was avoided. In this regard, the experiences of related studies with the same model were used to define the ranges for each parameter ([13]). Daily models were used for all the sensitivity analyses. Assessment of the model performance was done both visually and statistically using the objective functions according to [14] and also [15] for both normal and logarithmic values $\left(\mathrm{R}_{\text {eff }}\right.$ and $\left.\log \mathrm{R}_{\text {eff }}\right)$.

\subsection{Water Balance Analysis}

A summary of the simulated and observed discharges at the outlet of the subcatchment shows that the water balance closure was achieved at $127 \mathrm{~mm}$ and 119 mm per year for the $\mathrm{Q}_{\text {simulated }}$ and $\mathrm{Q}_{\text {observed }}$ for the Nyangores Sub-catchment respectively. A simple water balance closure using the water balance equation shows $457 \mathrm{~mm}$ of precipitation could not be accounted for. The $\mathrm{Q}_{\text {simulated }}$ and $\mathrm{Q}_{\text {observed }}$ for the Amala Sub-catchment were found to be $318 \mathrm{~mm}$ and $188 \mathrm{~mm}$ per year respectively. However the $279 \mathrm{~mm}$ of precipitation could not be accounted for but the results can be attributed to the interpolation method used either for the rainfall quantification or abstraction of the rivers' water. 


\subsection{Sensitivity Analysis}

The sensitivity analysis was done to calibration parameters of HBV Light model to determine the parameters that influence the model performance more than the others. The sensitivity analyses were carried out for the soil moisture routine, response and routing routines. The results are shown in Figure 6. The analysis was done by reducing and increasing the final calibration values by $10 \%$ and the results plotted in a graph.

From the sensitivity analysis, the results show that the coefficient of storage $\mathrm{K}_{0}$ was the most sensitive of all the calibration parameters. The results show that a slight change of this value gives a great variation in the model performance. The LP, BETA and FC are also sensitive in that order. Other parameters such as UZL, $\mathrm{K}_{1}$ and $\mathrm{K}_{2}$ show very low sensitivity to the model performance.

\subsection{Effect of Varying Time Steps}

When the computational time step was increased from daily to 15 days and 30 days' time step by using aggregated 15 and 30 days data sets respectively, the new calibration results gave better model performance for the two sub-catchments as compared to daily simulations. This was expected as large daily fluctuations during the wet season were smoothened out. The results show that the simulated average peak discharge was higher than the observed values, except during the periods 1999/2001 and 2004/2005 for Nyangores and 2003/2004 and 2006/2007 for Amala. The model efficiencies for the 15 days were, $R_{\text {eff }}>0.79$ and $R_{\text {eff }}>0.68$ for Nyangores and Amala respectively. Also the mean annual $(\Delta Q)$ differences were negligible in both sub-catchments. Interestingly, low flows were better simulated by the model in the Amala sub-catchment as compared to Nyangores.

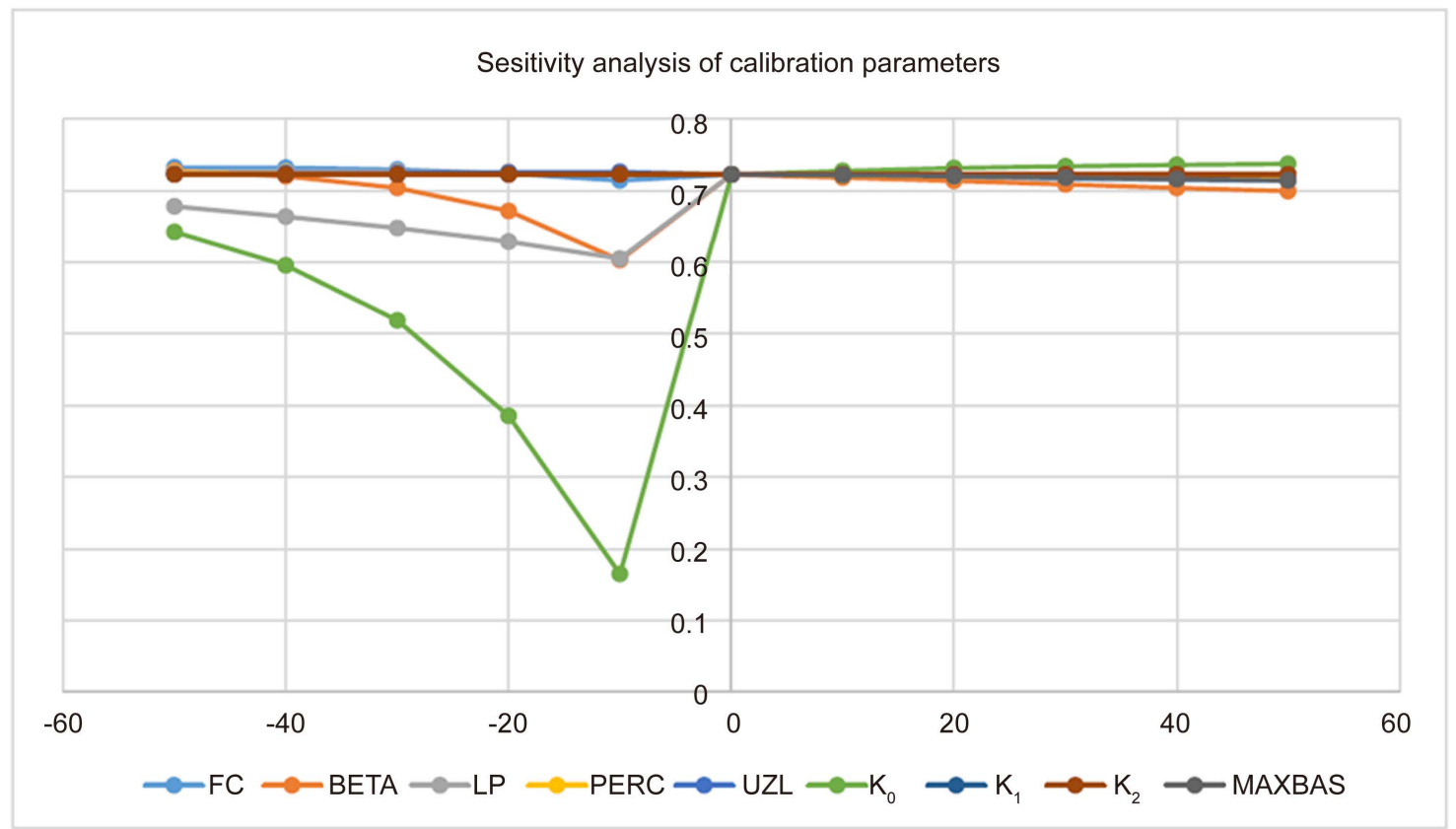

Figure 6. HBV model sensitive parameters analysis. 
The $\log \mathrm{R}_{\text {eff }}$ was $>0.71$ and $>0.62$ during the calibration and validation period respectively.

\subsection{Partitioning of the Flow Hydrograph}

The model was able to partition the total hydrograph into three components; the mean annual direct runoff $\left(\mathrm{Q}_{\mathrm{DR}}\right)$, the interflow $\left(\mathrm{Q}_{\mathrm{IF}}\right)$ and the base flow $\left(\mathrm{Q}_{\mathrm{BF}}\right)$ as summarised in Table 3.

Generally, the base flow is noticeably dominant in the Nyangores sub-catchment at $85 \%$ as compared to that of Amala sub-catchment at $20 \%$. The direct runoff is however dominant in Amala at $80 \%$ as compared to Nyangores at $15 \%$. The large difference in the runoff components between the two sub-catchments, demonstrates a distinct difference in the fast response characteristics between the two. These findings are supported by previous studies done by [16]. These researchers found out that Nyangores had higher infiltration than Amala. In this research, the ground water run-off was assumed to be the base flow. The results clearly demonstrate that the dry season runoff of the Mara River is largely sustained by ground water storage from the two sub-catchments.

\subsection{Model Performance Efficiency}

The model performance efficiency was carried out using the established statistical criteria such as NSE and $\mathrm{R}^{2}$. In addition to these indices, visual evaluation of the hydrographs was carried out in evaluating the simulation of peaks, low flows, recessions and timings. However, for model comparison of these efficiencies it is challenging to do so if the modelling time periods are different. However, for purposes of how efficient the model was in simulating the observed flow, the indices were found to be sufficient in determining the HBV model performance as given in Figure 7.

Figure 7 shows that the HBV Light model performed better in comparison to either SWAT or STREAM Model in simulating the hydrograph of the Nyangores and Amala Rivers. However, the STREAM model had a higher $\mathrm{R}^{2}$ efficiency both at the calibration and validation as compared to HBV.

\section{Conclusions}

The Mara River Basin is facing unprecedented threat as a result of deforestation,

Table 3. Statistics of direct runoff $\mathrm{Q}_{\mathrm{DR}}$ and base flow $\mathrm{Q}_{\mathrm{BF}}$ components from 1997 to 2008.

\begin{tabular}{lccc}
\hline & & \multicolumn{2}{c}{ Run-off component } \\
\hline \multicolumn{2}{c}{ Catchment representation } & $\mathrm{Q}_{\mathrm{DR}}$ & $\mathrm{Q}_{\mathrm{BF}}$ \\
\hline Nyangores & Mean Q (mm/a) & 18 & 101 \\
& $\%$ to total & $15 \%$ & $85 \%$ \\
Amala & Mean Q (mm/a) & 151 & 37 \\
& $\%$ to total & $80 \%$ & $20 \%$ \\
\hline
\end{tabular}




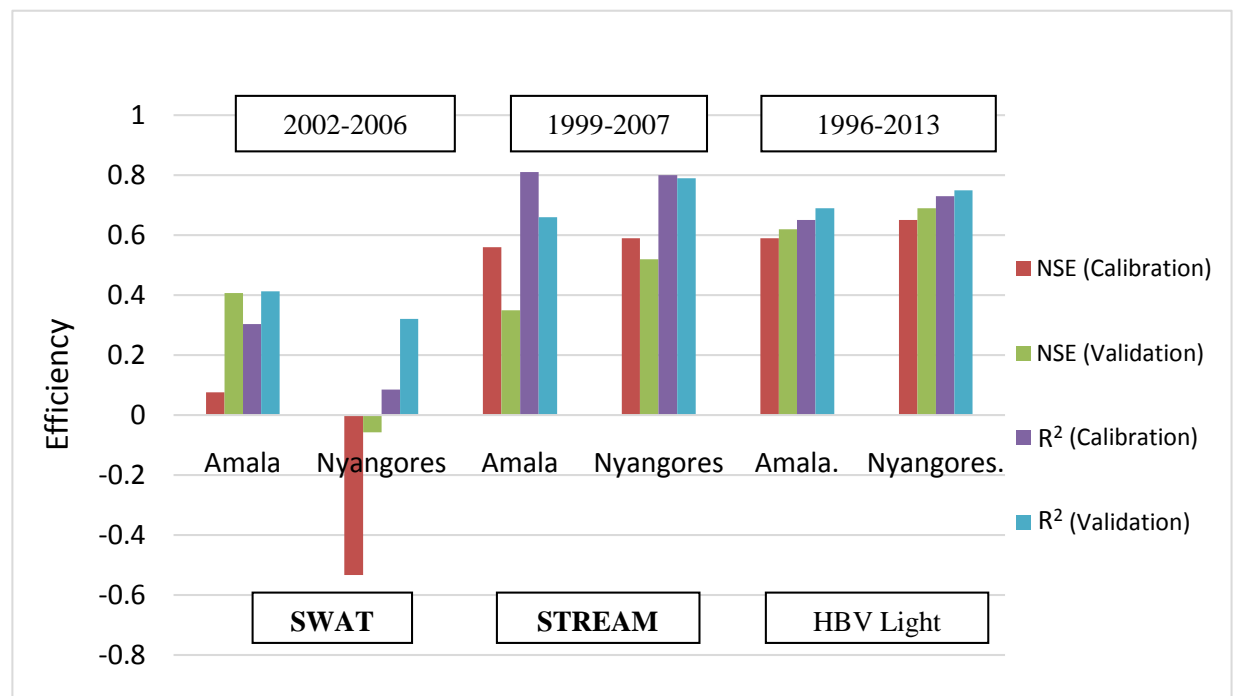

Figure 7. Comparison of SWAT, STREAM and HBV light models performance efficiencies.

expansion of agriculture, human settlement, sedimentation and erosion, flooding and low flows. Therefore, understanding the relation between the natural processes and anthropogenic activities that occur in the basin requires a reliable representation of the relevant hydrologic activities. The research assessed the ability of the HBV Light Model in simulating the long-term rainfall-runoff of the basin. The overall objective of the study was to apply a conceptual model simulating Mara river runoff as a function of the satellite observed and in-situ rainfall data. Based on the research questions the study was answering in its bid to achieve this objective, the following conclusions can be made:

a) There is a linear relationship between the in-situ rainfall and measured runoff, and the runoff simulation model was developed on the basis of this relationship.

b) The model was found to be sensitive mostly on the response routine parameter, $\mathrm{K}_{0}$ which was responsible to the direct run-off (coefficient of storage in the upper zone), followed by soil moisture routine parameter BETA ( $\beta$ ) and LP. It can be concluded that the $\mathrm{K}_{0}$ parameter is affected by catchment parameters such land cover/land use (forests), infiltration or ground water storage capacity which in turn affects the evapotranspiration. Nyangores has the highest evapotranspiration and has the lowest $\mathrm{K}_{0}$ while Amala is assumed to have the least evapotranspiration has the highest $\mathrm{K}_{0}$.

c) Although the model tried to simulate the recession flow hydrographs giving the representation of catchment characteristics, it was not able to simulate well the peak flows in the catchment. The model over estimated the flow peaks which could be attributed to use of interpolated rainfall and discharge data where the data were missing.

d) The model's performance in terms of NSE and $\mathrm{R}^{2}$ were better as compared to previous rainfall-runoff modelling done using SWAT and STREAM model. The values for NSE were 0.65 and 0.59 for the calibration period and 0.69 and 
0.62 for the validation of Nyangores and Amala respectively.

\section{Acknowledgements}

The authors acknowledge the financial support from the Pan African University (PAUWES), Algeria.

\section{References}

[1] UNEP (2010) “Africa Water Atlas". Division of Early Warning and Assessment (DEWA). United Nations Environment Programme (UNEP). Nairobi, Kenya. Progress Press Limited, Malta. http://www.earthprint.com

[2] Abwoga, A.C. (2012) Modeling the Impact of Land Use Change on River Hydrology in Data Scarce Environments: A Case Study the Mara Basin in Kenya. M.Sc. Research Thesis, UNESCO-IHE, Institute for Water Education, Delft.

[3] Melesse, A.M., McClain, M., Wang, X., Abira, M. and Mutayoba, W. (2008) Modeling the Impact of Land-Cover and Rainfall Regime Change Scenarios on the Flow of Mara River, Kenya. World Environmental and Water Resources Congress 2008, 1-10. https://doi.org/10.1061/40976(316)558

[4] Mati, B.M., Mutie, S.H., Home, P. and Mtalo, F. (2008) Impacts of Land Use/Cover Changes on the Hydrology of the Transboundary Mara River, Kenya/Tanzania. Lakes and Reservoirs. Research and Management, 13, 169-177. https://doi.org/10.1111/j.1440-1770.2008.00367.x

[5] Mango, L.M., Melesse, A.M., McClain, M.E., Gann, D. and Setegn, S.G. (2011) Land Use and Climate Change Impacts on the Hydrology of the Upper Mara River Basin, Kenya: Results of a Modeling Study to Support Better Resource Management. Hydrology and Earth System Sciences, 15, 2245-2258. https://doi.org/10.5194/hess-15-2245-2011

[6] Mwania, J.M. (2014) Runoff Modeling of the Mara River using Satellite Observed Soil Moisture and Rainfall. Master's Research Thesis, Enschede, The Netherlands.

[7] WWAP (2012) The United Nations World Water Development Report 4: Managing Water under Uncertainty and Risk. UNESCO. Paris. http://publishing.unesco.org/ http://www.hydrol-earth-syst-sci.net/15/2245/2011/

[8] Bergström, S. (1976) Development and Application of a Conceptual Runoff Model for Scandinavian Catchments. SMHI, Reports RHO, 7.

[9] Bergström, S. (1995) The HBV Model. In: Singh, V.P., Ed, Computer Models of Watershed Hydrology. Water Resources Publications, Highlands Ranch, CO, 443-476.

[10] Lindström, G., Johansson, B., Persson, M., Gardelin, M., and Bergström, S. (1997) Development and Test of the Distributed HBV-96 Hydrological Model. Journal of Hydrology, 201, 272-288. https://doi.org/10.1016/S0022-1694(97)00041-3

[11] Seibert, J. and Vis, M.J. (2012) Teaching Hydrological Modeling with a User-Friendly Catchment-Runoff-Model Software Package. Hydrology and Earth System Sciences, 16, 3315-3325. https://doi.org/10.5194/hess-16-3315-2012

[12] Vis, M., Knight, R., Pool, S., Wolfe, W. and Seibert, J. (2015) Model Calibration Criteria for Estimating Ecological Flow Characteristics. Water, 7, 2358-2381. https://doi.org/10.3390/w7052358

[13] Uhlenbrook (2010) Analyzing Catchment Behavior through Catchment Modeling in the Gilgel Abay, Upper Blue Nile River Basin, Ethiopia. Hydrology and Earth 
System Sciences, 14, 2153-2165. https://doi.org/10.5194/hess-14-2153-2010

[14] Nash, J.E. and Sutcliffe, J.V. (1970) River Flow Forecasting through Conceptual Models, Part 1-A Discussion of Principles. Journal of Hydrology, 10, 282-290.

[15] Schaefli, B.A. (2007) Do Nash Values Have Value? Hydrological Processes, 21, 2075-2080. https://doi.org/10.1002/hyp.6825

[16] Dessu, S.B. and Melesse, A.M. (2012) Modelling the Rainfall-Runoff Process of the Mara River Basin using the Soil and Water Assessment Tool. Hydrological Processes, 26, 4038-4049. https://doi.org/10.1002/hyp.9205

Submit or recommend next manuscript to SCIRP and we will provide best service for you:

Accepting pre-submission inquiries through Email, Facebook, LinkedIn, Twitter, etc. A wide selection of journals (inclusive of 9 subjects, more than 200 journals)

Providing 24-hour high-quality service

User-friendly online submission system

Fair and swift peer-review system

Efficient typesetting and proofreading procedure

Display of the result of downloads and visits, as well as the number of cited articles

Maximum dissemination of your research work

Submit your manuscript at: http://papersubmission.scirp.org/

Or contact ijg@scirp.org 